\title{
Arabidopsis thaliana and Thlaspi caerulescens respond comparably to low zinc supply
}

\author{
Sangita Talukdar • Mark G. M. Aarts
}

Received: 1 July 2007 / Accepted: 31 August 2007 / Published online: 20 September 2007

(C) Springer Science + Business Media B.V. 2007

\begin{abstract}
The main objective of this research was to study the response of Arabidopsis thaliana L. and Thlaspi caerulescens J. \& C. Presl to different $\mathrm{Zn}$ supplies. The $A$. thaliana plants were exposed to $\mathrm{Zn}-$ deficiency $(0$ and $0.05 \mu \mathrm{M} \mathrm{Zn})$ and compared to the plants grown on media containing standard $\mathrm{Zn}$ $(2 \mu \mathrm{M}) . T$. caerulescens plants were also exposed to Zn-deficiency $(0.05 \mu \mathrm{M} \mathrm{Zn})$, but as this is a $\mathrm{Zn}$ hyperaccumulator species, also to high $\mathrm{Zn}(1,000 \mu \mathrm{M}$ $\mathrm{Zn})$. Plants were compared to plants grown on standard Zn media (100 $\mu \mathrm{M} \mathrm{Zn})$. Both A. thaliana and $T$. caerulescens were found to be heavily affected by $\mathrm{Zn}$ deficiency, showing similar retarded growth and reduced reproduction phenotypes, and even less reduction in biomass production in $T$. caerulescens than in $A$. thaliana. T. caerulescens plants were similarly affected when grown on high $\mathrm{Zn}$ concentrations, with comparable effects on reproductive tissues as seen on low Zn supply.
\end{abstract}

Keywords Arabidopsis · Thlaspi $\cdot$ Zn deficiency

Responsible Editor: Ismail Cakmak.

S. Talukdar • M. G. M. Aarts $(\bowtie)$

Laboratory of Genetics, Wageningen University,

Arboretumlaan 4,

6703 BD Wageningen, The Netherlands

e-mail: mark.aarts@wur.nl

\section{Introduction}

Contamination of soils with heavy metals, either by natural causes or due to pollution, often has pronounced effects on the vegetation, eventually characterised by the appearance of metallophytes: heavy metal-tolerant plant species. Some of these species are not only heavy metal tolerant but also heavy metal hyperaccumulating. The zinc $(\mathrm{Zn})$ hyperaccumulator species are defined to accumulate more than $10,000 \mu \mathrm{g}$ Zn per gram of dry weight (dw; 1\%, w/w; Baker and Brooks 1989), whereas most plants contain between 30 and $100 \mu \mathrm{g} \mathrm{Zn} \mathrm{g}^{-1} \mathrm{dw}$ and concentrations above $300 \mu \mathrm{g} \mathrm{Zn} \mathrm{g}{ }^{-1} \mathrm{dw}$ are generally toxic (Marschner 1995). Thlaspi caerulescens (Tc), is a model plant species to study metal hyperaccumulation and -tolerance (Assunção et al. 2003a). This species belongs to the Brassicaceae family and is known as a $\mathrm{Zn}$ hyperaccumulator, showing up to 30,000 $\mu \mathrm{g} \mathrm{Zn} \mathrm{g}^{-1} \mathrm{dw}$ foliar concentration (Brown et al. 1995). In addition, hyperaccumulation of $\mathrm{Cd}$ or $\mathrm{Ni}$ has been reported for a number of natural $T$. caerulescens populations from calamine and serpentine soils (Reeves and Brooks 1983; McGrath et al. 1993). The model plant species Arabidopsis thaliana, a metal non-accumulator, also belonging to the Brassicacae family, is the reference species in this research. A. thaliana is a suitable species as a comparative non-accumulator, based on its molecular 
similarity and because of its available genetic resources (Freeman et al. 2004).

All plants, either being an accumulator or nonaccumulator, need micronutrients for healthy growth and development. $\mathrm{Zn}$ is the second most abundant transition metal (after Fe) in biological systems, including plants (Worlock and Smith 2002). Zn is both stable and inert to oxidoreduction, in contrast to the neighbouring transition elements in the periodic table [for review see Vallee and Auld (1990) and Vallee and Falchuk (1993)]. This makes Zn stable in a biological medium in which the redox potential is in constant flux. $\mathrm{Zn}$ is an essential element that is employed in a wide range of biochemical and biophysical roles. It is required to maintain the structural stability of macromolecules and to serve as a cofactor for more than 300 metabolic enzymes represented in all enzyme classes (Broadley et al. 2007), including $\mathrm{Cu}-\mathrm{Zn}$ superoxide dismutase, alcohol dehydrogenase and RNA polymerase, and DNAbinding proteins (Marschner 1995; Guerinot and Eide 1999). It also plays a prominent role in gene expression as a structural component in a large number of $\mathrm{Zn}$-dependent transcription factors (Worlock and Smith 2002), predominantly $\mathrm{Zn}$ finger proteins (Broadley et al. 2007).

$\mathrm{Zn}$ available to plants is present in the soil solution or is adsorbed in a labile (easily desorbed) form. The soil factors affecting the availability of $\mathrm{Zn}$ to plants are those which control the amount of $\mathrm{Zn}$ in the soil solution and its sorption/desorption from/into the soil solution. These factors include: the total $\mathrm{Zn}$ content, $\mathrm{pH}$, organic matter content, calcium carbonate content, redox conditions, microbial activity in the rhizosphere, soil moisture status, concentrations of other trace elements, concentrations of macronutrients (especially phosphorus) and climate (Broadley et al. 2007). The availability of $\mathrm{Zn}$ can be limited in certain soils, especially in the calcareous ones (Grusak and DellaPenna 1999). Severe Zn deficiency generally leads to reduction in internodal growth with a consequent rosette-like development, small and discoloured leaves, poor root formation and reduced seed and fruit production (Marschner 1995). Zn deficiency also leads to an impaired response to oxidative stress, likely due to a reduction in superoxide dismutase levels (Hacisalihoglu et al. 2003). $\mathrm{Zn}$ is the most common crop micronutrient deficiency (Broadley et al. 2007), and therefore it constitutes a significant agricultural problem, particularly in cereals, limiting crop production and quality (Guerinot and Eide 1999; Hacisalihoglu et al. 2003). On the other hand, excess of $\mathrm{Zn}$ leads to $\mathrm{Zn}$ toxicity, which induces chlorosis in young leaves, probably via competition with $\mathrm{Fe}$ and $\mathrm{Mg}$ (Marschner 1995), and arrests root and eventually shoot growth.

Although Zn deficiency studies have been described for several plant species, there is no report on the visible response on the plant growth and development to reduced $\mathrm{Zn}$ supply of the general reference species $A$. thaliana. As $\mathrm{Zn}$ hyperaccumulator species are suggested to not only acquire but also require more $\mathrm{Zn}$ than non-accumulator species considering their constitutively higher expression of $\mathrm{Zn}$ uptake transporters (Becher et al. 2004; Hammond et al. 2006; Van de Mortel et al. 2006; Weber et al. 2004) we also examined the response of the hyperaccumulator T. caerulescens. In addition we examined the response of $T$. caerulescens to high $\mathrm{Zn}$ exposure, to which this species is generally tolerant (Assunção et al. 2003a).

\section{Materials and methods}

To determine the response of $A$. thaliana L. (accession Columbia) and T. caerulescens J. \& C. Presl (accession La Calamine) to $\mathrm{Zn}$, the plants were grown on modified half Hoagland's solution supplied with different $\mathrm{ZnSO}_{4}$ concentrations. The nutrient medium was refreshed every week. A. thaliana, like any other non-accumulator, needs very low supply of $\mathrm{Zn}$, hence $0 \mu \mathrm{M} \mathrm{ZnSO}_{4}$ (where $\mathrm{Zn}$ was left out of the media) was used to create a true $\mathrm{Zn}$-deficient condition. In addition, plants were also grown on half Hoagland's solution supplied with $0.05 \mu \mathrm{M} \mathrm{ZnSO}_{4}$ to allow plants to be able to take up a low amount of $\mathrm{Zn}$ from the medium. In case of plants grown on $0 \mu \mathrm{M} \mathrm{Zn}$, the $\mathrm{Zn}$ content in the tissues are below the range of detection by atomic absorption spectroscopy (AAS), which was used for the measurements of metal concentrations (Assunção et al. 2003b). In case of $T$. caerulescens, $100 \mu \mathrm{M} \mathrm{ZnSO}_{4}$ was used as the concentration on which the plants grow healthy (Van de Mortel et al. 2006). $0.05 \mu \mathrm{M}$ Zn was used as a Zndeficient concentration. In addition to deficient and sufficient supply, T. caerulescens was also exposed to high $\mathrm{Zn}$ supply $\left(1,000 \mu \mathrm{M} \mathrm{ZnSO}_{4}\right)$. 
All the plants were first grown for two weeks on plates with half MS (Murashige and Skoog 1962) medium, containing 1\% agar and were then transferred to hydroponics using solutions of half Hoagland's and with different $\mathrm{Zn}$ concentrations as described above. Twelve plants for each concentration of $\mathrm{Zn}$ were grown in a climate-controlled growth chamber as described by Van de Mortel et al. (2006), and the data were collected based on these plants. Plants were grown for a full life-cycle. A. thaliana was phenotypically examined for a period of eight weeks, and T. caerulescens for a period of 16 weeks. Thereafter plants were left for the seeds to mature, which were collected. For each growth treatment, two biological replicas were used. At harvest, plants of $A$. thaliana $\mathrm{Col}$ (a winter annual) were dead and plants of $T$. caerulescens LC (a perennial) were still growing.

Germination experiments were performed with around 1-month-old seeds (from Zn-deficient and Zn-sufficient grown plants) in Petri dishes with water-imbibed filter paper. The seeds were incubated in a climate-controlled growth cabinet $\left(25^{\circ} \mathrm{C}\right.$ day; $16 \mathrm{~h}$ day with illumination at a light intensity of $120 \mu \mathrm{mol} \mathrm{m}{ }^{-2} \mathrm{~s}^{-1}$ ), either after stratification (4 days at $4^{\circ} \mathrm{C}$; A. thaliana) or without stratification (T. caerulescens).

\section{Results}

Response of A. thaliana plants to low $\mathrm{Zn}$

In general, $\mathrm{Zn}$ deficiency has a very serious effect on growth and development of $A$. thaliana plants. When plants are grown for four weeks under $\mathrm{Zn}$-deficient conditions $(0 \mu \mathrm{M} \mathrm{Zn})$ they are chlorotic and much smaller compared to plants grown for the same time under Zn-sufficient conditions ( $2 \mu \mathrm{M} \mathrm{Zn;} \mathrm{Fig.} \mathrm{1a,b).}$ Shoot and root weight is reduced by five- to sevenfold (Fig. 2a). Main stem and root length also shows a reduction, of seven- to ten-fold, when measured over a period of 8 weeks (Fig. 2c,d). The average rosette leaves were smaller in size, cripple and chlorotic (Fig. 1c,d) and the mean rosette leaf weight was reduced 2.7-fold (Fig. 2b). The $\mathrm{Zn}$ deficient flower buds were yellow (Fig. 1f) compared to those of the control plants (Fig. 1e) and their flowers were poorly developed (Fig. 1g,h). The Zn-deficient pistils were smaller in size than the Zn-sufficient ones (Fig. 1i,j) and also the siliques were shorter than the siliques on Zn-sufficient plants (Fig. 1k), with less seeds per silique (Figs. 11,m and 3c). When measured, silique length was reduced by two-fold (Fig. 3a) and silique weight by three-fold (Fig. 3b) of Zn-deficient plants compared to $\mathrm{Zn}$-sufficient plants. The Zn-deficient seeds were smaller and weighed less than seeds of Zn-sufficient plants (Fig. 1n,o). This also affected the germination ability of $\mathrm{Zn}$-deficient seeds, leading to a strong reduction in germination percentage (Fig. 3d), most likely due to the loss of viability rather than differences in dormancy. Such dramatic differences in growth and development caused by the reduction in $\mathrm{Zn}$ supply are likely to also affect the $\mathrm{Zn}$ concentration of the $\mathrm{Zn}$-deficient plants. When measured, indeed the $\mathrm{Zn}$ concentration of the $\mathrm{Zn}$-deficient plants was hardly measurable and significantly lower than that of the $\mathrm{Zn}$-sufficient plants in all organs that were analysed (Fig. 4). However, despite the very low $\mathrm{Zn}$ concentrations there were no differences in distribution of $\mathrm{Zn}$ over the investigated organs (data not shown).

Response of T. caerulescens plants to $\mathrm{Zn}$

The response of $T$. caerulescens to $\mathrm{Zn}$ deficiency was studied in a similar way as in A. thaliana. However, as $T$. caerulescens is a $\mathrm{Zn}$ hyperaccumulator species, plants were also exposed to high $\mathrm{Zn}(1,000 \mu \mathrm{M})$. Rather than $0 \mu \mathrm{M} Z \mathrm{Zn}, 0.05 \mu \mathrm{M} \mathrm{Zn}$ was used as $\mathrm{Zn}$ deficient concentration and the $\mathrm{Zn}$-sufficient concentration was raised to $100 \mu \mathrm{M} \mathrm{Zn}$ (according to Van de Mortel et al. 2006). As T. caerulescens has a much longer life cycle than A. thaliana, plants were grown for a considerably longer time on hydroponics before their phenotypes were examined.

Overall plants were smaller when grown for 16 weeks under $\mathrm{Zn}$-deficiency and high-Zn compared to plants grown on sufficient Zn (Fig. 5a). This led to a reduction in shoot and root weight by three- to fourfold under Zn-deficiency and high $\mathrm{Zn}$ conditions compared to Zn-sufficiency (Fig. 6a). The rosette leaves are smaller of plants grown under $\mathrm{Zn}$-deficiency and high $\mathrm{Zn}$ compared to plants grown under $\mathrm{Zn}$ sufficiency (Fig. 5b). Like for A. thaliana, the leaves of $\mathrm{Zn}$-deficient plants were showing signs of chlorosis compared to $\mathrm{Zn}$-sufficient leaves. In contrast, nonchlorotic leaves of plants grown on high $\mathrm{Zn}$ were 

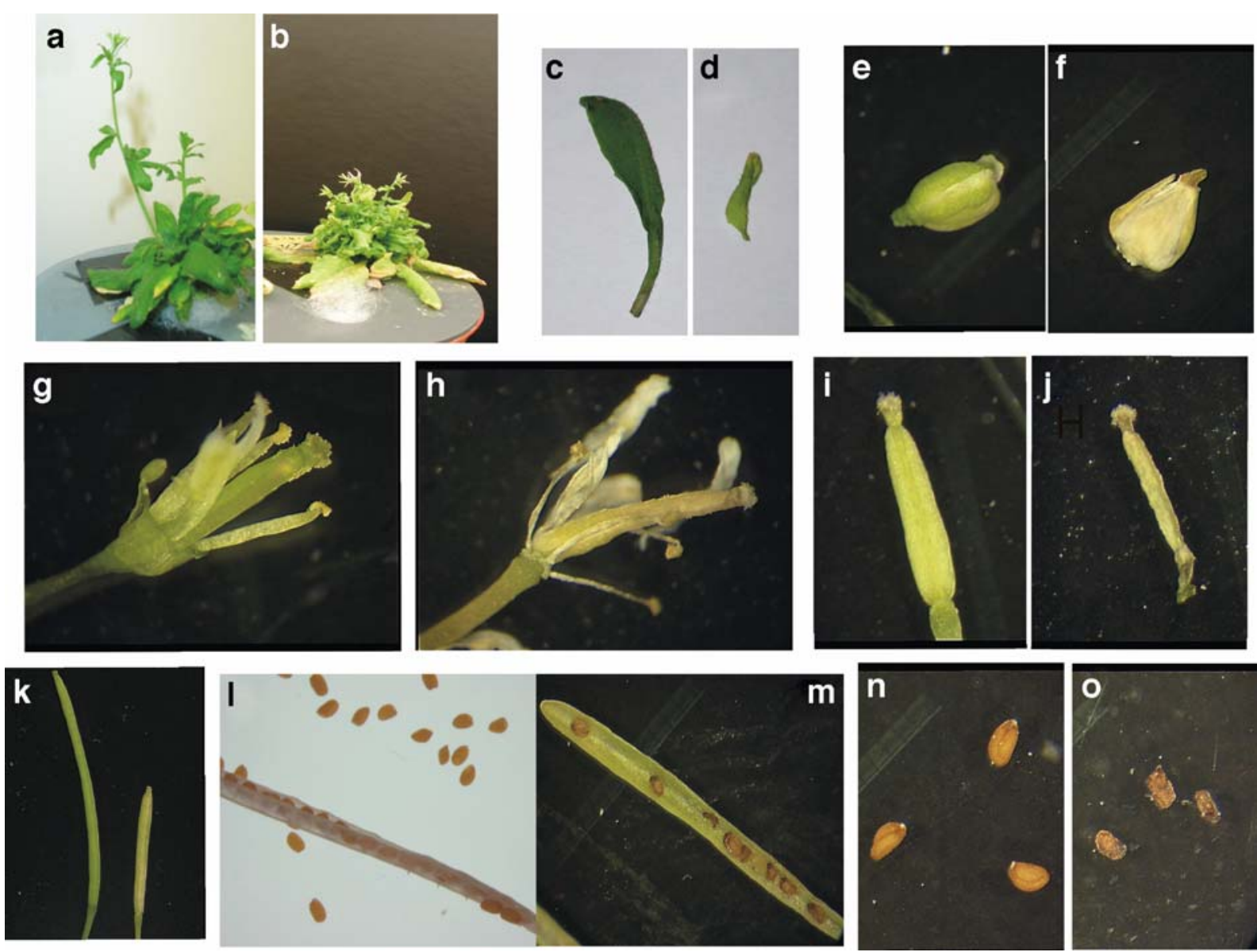

Fig. 1 Phenotypic differences of $A$. thaliana plants grown under $\mathrm{Zn}$-sufficient or $\mathrm{Zn}$-deficient conditions. A. thaliana plants are grown on hydroponic medium containing $2 \mu \mathrm{M}$ $\mathrm{ZnSO}_{4}$ (Zn-sufficient medium) or on the same medium without any $\mathrm{Zn}$ added ( $\mathrm{Zn}$-deficient medium). Organs were examined after 4 weeks of growth on hydroponics medium with the exception of siliques and seeds that were collected from 14-

darker green than those from Zn-sufficient plants. Reduction in leaf weight was 2.5 -fold under $\mathrm{Zn}$ deficiency and high $\mathrm{Zn}$ conditions, compared to $\mathrm{Zn}$ sufficient plants (Fig. 6b). The inflorescences of plants grown under Zn-deficiency and high $\mathrm{Zn}$ were generally not properly developed and often senesced prematurely (Fig. $5 \mathrm{c}-\mathrm{e}$ ). In total 12 plants grown on sufficient $\mathrm{Zn}$ produced 30 inflorescences after 16 weeks of hydroponic growth, whereas plants grown under Zn-deficiency or high $\mathrm{Zn}$ produced ten respectively four inflorescences. The flower buds in the $\mathrm{Zn}$ deficient and high $\mathrm{Zn}$ plants generally turned chlorotic and eventually necrotic prematurely (Fig. 5f,h). Most week-old plants. a, c, e, g, i, $\mathbf{l}$ and $\mathbf{m}$ show parts of plants grown on $\mathrm{Zn}$-sufficient medium; $\mathbf{b}, \mathbf{d}, \mathbf{f}, \mathbf{h}, \mathbf{j}, \mathbf{m}$ and $\mathbf{o}$ show parts of plants grown on Zn-deficient medium. a, b Plants grown for 4 weeks on hydroponic medium. c, d Rosette leaf, e, f flower bud, $\mathbf{g}, \mathbf{h}$ flower with sepals and petals removed, $\mathbf{i}, \mathbf{j}$ pistil, $\mathbf{k}$ silique of $\mathrm{Zn}$-sufficient (left) and -deficient plant (right), $\mathbf{l}, \mathbf{m}$ opened silique with seeds and $\mathbf{n}, \mathbf{o}$ mature seeds

of the flower-buds in $\mathrm{Zn}$-deficient plants failed to open. Also the few siliques that formed on $\mathrm{Zn}$-deficient and high $\mathrm{Zn}$ plants were chlorotic and senesced prematurely (Fig. 5i,k), whereas in the Zn-sufficient plants they were green (Fig. 5j). As can be expected, the numbers of seeds in the siliques were lower on Zn-deficient and high $\mathrm{Zn}$ plants, compared to $\mathrm{Zn}$-sufficient plants.

Like for A. thaliana, the $\mathrm{Zn}$ concentration of the different plant organs from Zn-deficient, Zn-sufficient and high Zn plants were compared (Fig. 6d). In each condition the $\mathrm{Zn}$ concentration in the shoots was higher than in the roots. Although the $\mathrm{Zn}$ supply under $\mathrm{Zn}$ deficiency was higher for $T$. caerulescens 

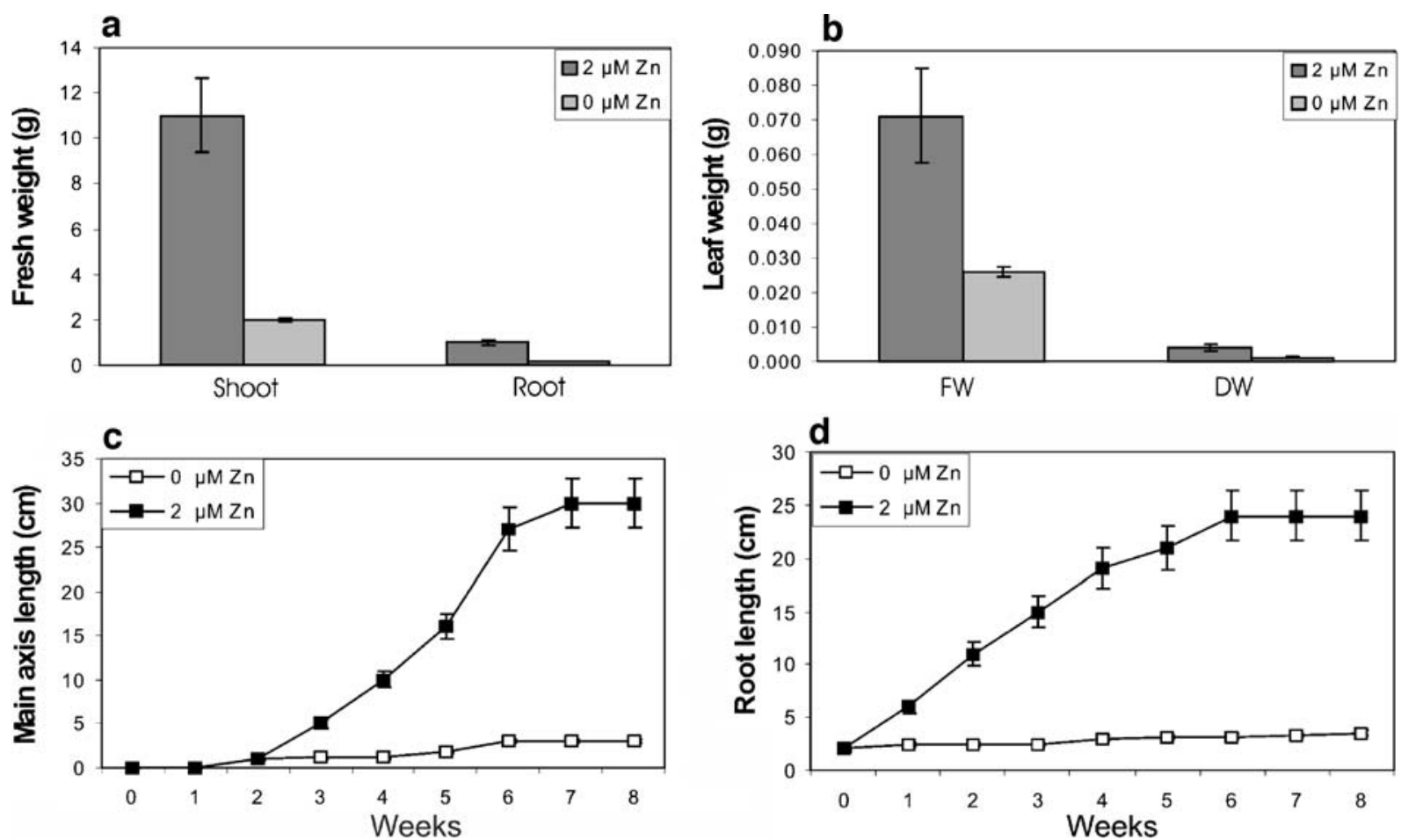

Fig. 2 Growth characteristics of $A$. thaliana plants grown for 8 weeks on $\mathrm{Zn}$-sufficient ( $2 \mu \mathrm{M} \mathrm{Zn})$ or Zn-deficient $(0 \mu \mathrm{M} \mathrm{Zn})$ hydroponic medium. a Average shoot and root fresh weight; b

than for A. thaliana, the $\mathrm{Zn}$ concentration of the $\mathrm{Zn}$ deficient plants was very low. The $\mathrm{Zn}$ concentration in the roots of plants grown on high $\mathrm{Zn}$ was 2.3-fold higher after 16 weeks of exposure than in roots of $\mathrm{Zn}$ -

average leaf fresh weight $(F W)$ and dry weight $(D W ; n=5)$; c Average length of main stem axis; and $\mathbf{d}$ average longest root length. Twelve plants were sampled, error bars indicate SE

sufficient plants. In leaves it was around 3.0-fold higher. The shoot-to-root ratio after 16 weeks of hydroponic growth was 2.7 for $\mathrm{Zn}$-sufficient plants and 3.1 for high $\mathrm{Zn}$ plants.

Fig. 3 The effect of differences in $\mathrm{Zn}$ supply on $A$. thaliana silique characteristics. a Average mature silique length and $\mathbf{b}$ silique weight; $\mathbf{c}$ average number of seeds per silique (five siliques per plant, 12 plants); and $\mathbf{d}$ percentage of seed germination
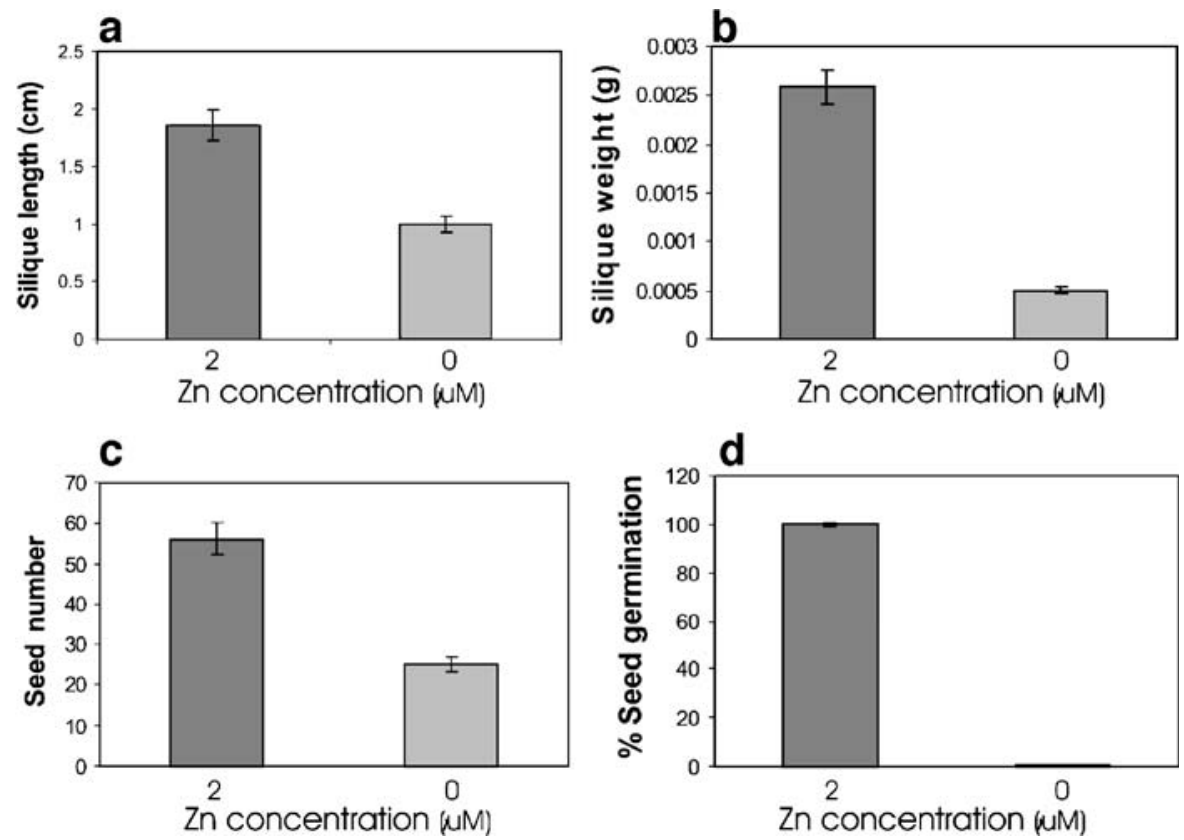

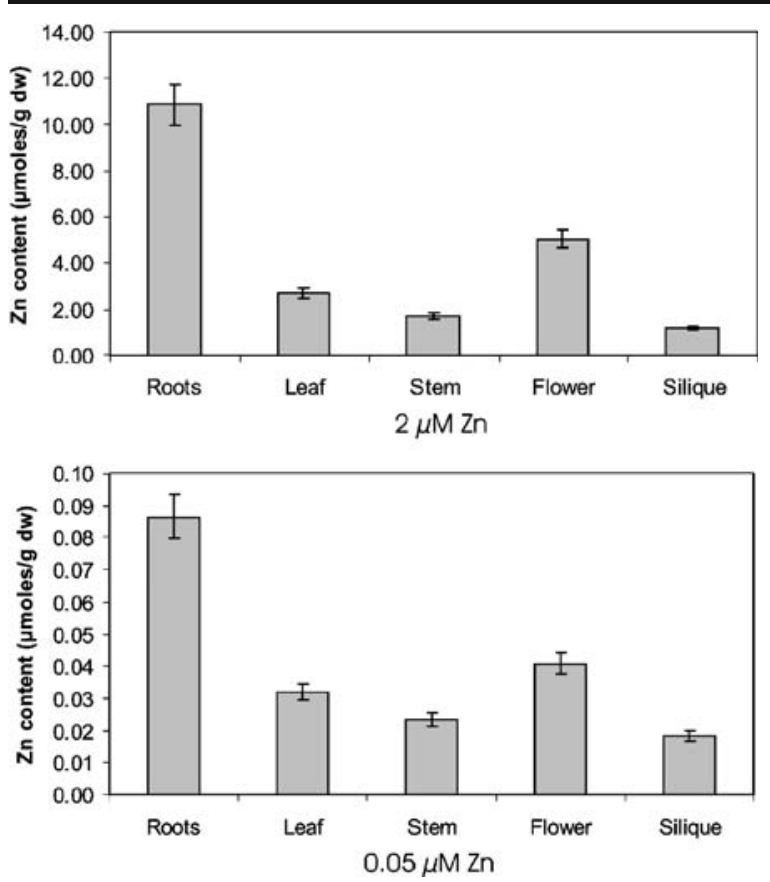

Fig. 4 Comparison of the $\mathrm{Zn}$ content in roots, leaves, stems, flowers and siliques of $A$. thaliana plants grown on hydroponic media with $2 \mu \mathrm{M}$ or $0.05 \mu \mathrm{M} \mathrm{Zn}$ supply for 8 weeks

\section{Discussion}

The Zn-deficiency phenotype of $A$. thaliana plants was studied. In general plants showed all the characteristics as described previously for Zn-deficient plants in several other species: reduction of internodal growth with an enhanced rosette-like development ('rosetting'), chlorosis, poor root formation and reduced seed and fruit production (Marschner 1995; Broadley et al. 2007). The striking reduction in leaf size we observed is typically induced by $\mathrm{Zn}$ deficiency, as was also found in other species ('little leaf' syndrome; Marschner 1995). The increasing chlorosis in the leaf is assumed to be due to the negative effect of $\mathrm{Zn}$ deficiency on photosynthesis. The reduced height of $\mathrm{Zn}$-deficient plants, compared with Zn-sufficient plants, seems to be related with alterations in the auxin status of the plant. A previous study on the relationship between $\mathrm{Zn}$ and auxin status has shown that a decrease in auxin precedes the appearance of visible symptoms of $\mathrm{Zn}$ deficiency in tomato and sunflower suggesting that $\mathrm{Zn}$ is required for auxin production. The effect of a reduction in auxin levels was only observed in Zn-deficient plants, whereas it was not observed in Mn-deficient or $\mathrm{Cu}$ - deficient plants (Skoog 1940). Such response should be visible at the gene expression level. Although a whole-transcriptome analysis of response to $\mathrm{Zn}$ deficiency has not been reported for shoots, Van de Mortel et al. (2006) found five auxin responsive genes to be higher expressed in roots of Arabidopsis plants exposed for a week to $\mathrm{Zn}$ deficiency, compared to $\mathrm{Zn}$ sufficient plants, suggesting indeed there is a change in auxin regulated growth.

Zn-deficient plants are also known to have an impaired response to oxidative stress, likely due to a reduction in superoxide dismutase levels (Hacisalihoglu et al. 2003). In addition, Sharma et al. 1995 showed a requirement of $\mathrm{Zn}$ for stomatal opening in cauliflower. Zn-deficiency also induced increased epicuticular wax deposits, lamina thickness, degree of succulence, water saturation deficit, diffusive resistance, and proline accumulation and decreases in carbonic anhydrase activity, water potential, stomatal aperture, and transpiration in the leaves of cauliflower plants (Sharma et al. 1995). Such is also likely to occur in Arabidopsis, which has been supported by alterations in gene expression levels for these stress related processes (Van de Mortel et al. 2006). These phenomena together are likely to cause the severe imbalance of growth and development in A. thaliana.

The reproductive organs, the most important parts of the plant, were found to be heavily affected in the $\mathrm{Zn}$-deficient $A$. thaliana plant. The $\mathrm{Zn}$ concentration in the flowers is the second highest (after the roots) in the $\mathrm{Zn}$-sufficient plants, indicating the importance of $\mathrm{Zn}$ for proper development and function of the reproductive organs. In the $\mathrm{Zn}$-deficient plants, the $\mathrm{Zn}$ content in flowers is equally reduced to very low levels, like in all parts of the plants, but in view of the higher demand, this likely has more drastic effects on the metabolic performance of the cells in these organs. Polar 1970 showed that in Vicia faba anthers, and especially pollen contained the highest concentration of $\mathrm{Zn}$ when compared to other parts of the plants. $\mathrm{Zn}$ is needed for pollen tube growth and pollination. Reason can be the high rate of RNA synthesis that occurs during the elongation of the pollen tubes (Mascarenhas and Goralnick 1971). This process needs RNA polymerase, which is a $\mathrm{Zn}$ requiring enzyme. Like for $A$. thaliana, $\mathrm{Zn-deficient}$ pea plants were found to have smaller pods and less developed seeds compared to Zn-sufficient plants (Reed 1944). Rather than problems with anther 
Fig. 5 Phenotypic differences of $T$. caerulescens plants cient and high $\mathrm{Zn}$ hydroponic medium. Plants were grown for 16 weeks on medium with $0.05 \mu \mathrm{M} \mathrm{Zn}$ (deficient), $100 \mu \mathrm{M} \mathrm{Zn}$ (sufficient) or 1,000 $\mu \mathrm{M} \mathrm{Zn}$ (high $\mathrm{Zn}$ ). Organs from $\mathrm{Zn}$ deficient plants are shown in $\mathbf{c}, \mathbf{f}$ and $\mathbf{i}$, organs from Zn-sufficient plants in $\mathbf{d}, \mathbf{g}$ and $\mathbf{j}$ and organs from highZn plants in e, h, k. a Plants grown on deficient (left), sufficient (middle) and high $\mathrm{Zn}$ (right); b median rosette leaf from deficient (left), sufficient (middle) and high Zn (right) plant; c-e inflorescence; f-h flower bud; and $\mathbf{i}-\mathbf{k}$ silique grown on deficient, suffi-
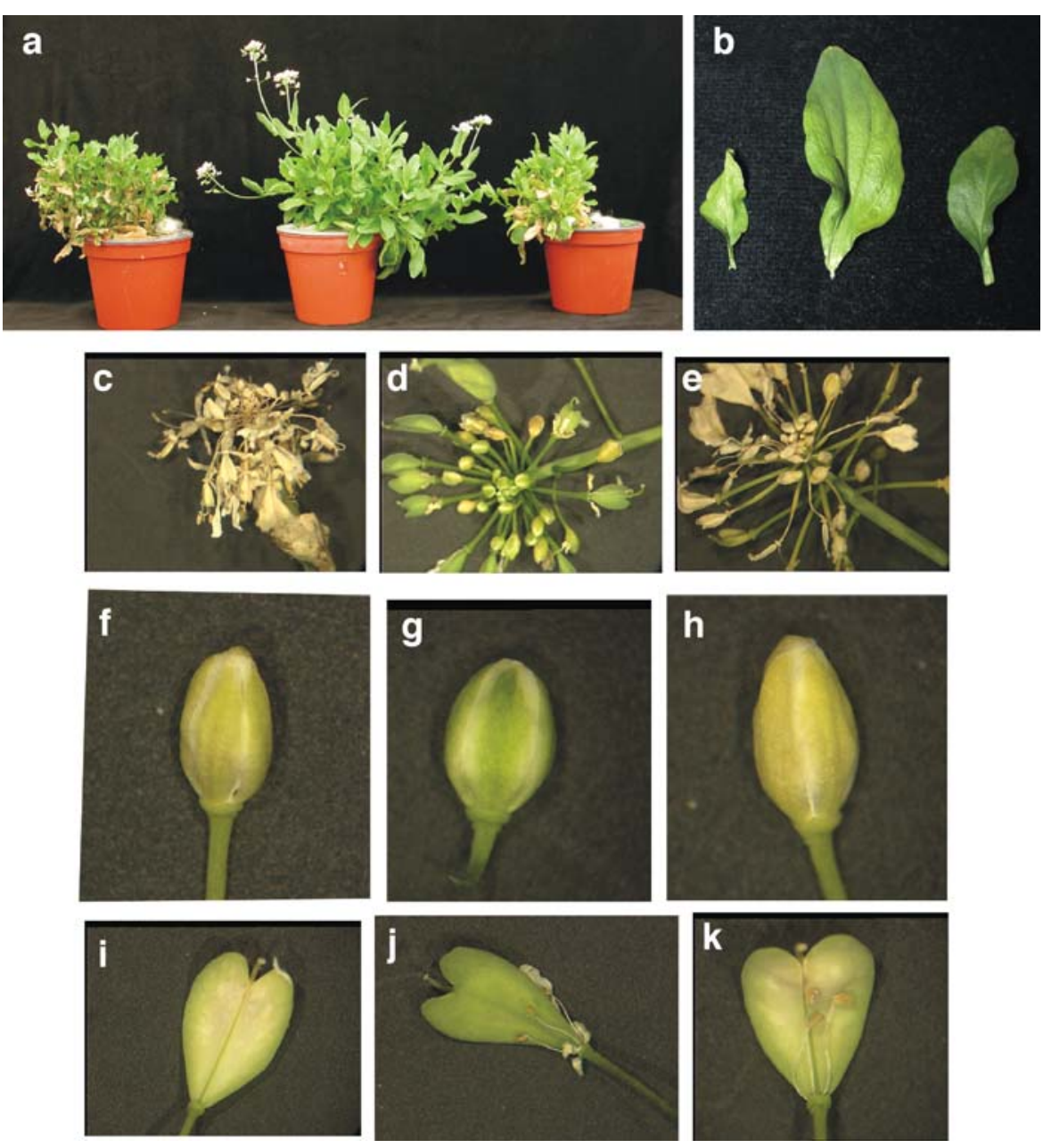

development and pollen tube growth, failure to produce good seeds was attributed to irregularities in the growth of the ovules (Reed 1944). Necrosis of cells in the funiculus and adjacent portions of such ovules was also frequently observed, surrounded by areas in which the cells were generally hypoplastic, vacuolated, often showing evidence of cytolysis which destroyed their protoplasmic integrity (Reed 1944).

Over all, the negative effects of $\mathrm{Zn}$ deficiency on growth and development of $A$. thaliana plants are well in line with those observed for other plant species. In general, the same Zn-deficiency related phenomena were observed for T. caerulescens as for A. thaliana. This was somewhat unexpected, considering that $T$. caerulescens is a $\mathrm{Zn}$ hyperaccumulator, which is suggested to have a higher requirement for $\mathrm{Zn}$ for optimal growth than A. thaliana (Van de Mortel et al. 2006). However, the difference in $\mathrm{Zn}$ requirement has never been examined in great detail.
T. caerulescens plants from the metallicolous accession La Calamine growing on hydroponic solutions containing $2 \mu \mathrm{M} \mathrm{ZnSO} 4$ occasionally show $\mathrm{Zn}$ deficiency symptoms (A.G.L. Assunção, personal communication) suggesting indeed that there is a higher $\mathrm{Zn}$ requirement. Optimal concentrations in hydroponics are likely to be in the range between 2 to over $100 \mu \mathrm{M} \mathrm{Zn}$, depending on the tolerance of the accessions. Accessions obtained from non-metallicolous sites show signs of toxicity at $50 \mu \mathrm{M} \mathrm{Zn}$, but accessions from metallicolous sites show toxicity symptoms only when exposed to concentrations of $1,000 \mu \mathrm{M}$ or higher (Assunção et al. 2003b). In this study plants from the metallicolous and $\mathrm{Zn}$ hypertolerant accession La Calamine were used (Assunção et al. 2003b).

At the end of the exposure, plants from both species showed comparable phenotypes. Although $T$. caerulescens plants were exposed to $\mathrm{Zn}$-deficiency 
Fig. 6 The effect of differences in $\mathrm{Zn}$ supply on plant growth and $\mathrm{Zn}$ concentration of $T$. caerulescens plants. a Average root and shoot fresh weight $(F W)$ and dry weight $(D W)$ per plant and $\mathbf{b}$ average rosette leaf fresh weight of plants grown at deficient (0.05), sufficient (100) and high $\mathrm{Zn}$ $(1,000 \mu \mathrm{M} \mathrm{Zn})$; and $\mathbf{c}$, d comparison of the $\mathrm{Zn}$ concentration of $T$. caerulescens plants grown on deficient (0.05), sufficient (100) and high $\mathrm{Zn}(1,000)$. Open symbols Shoots; closed symbols roots. Twelve plants were sampled, error bars indicate SE
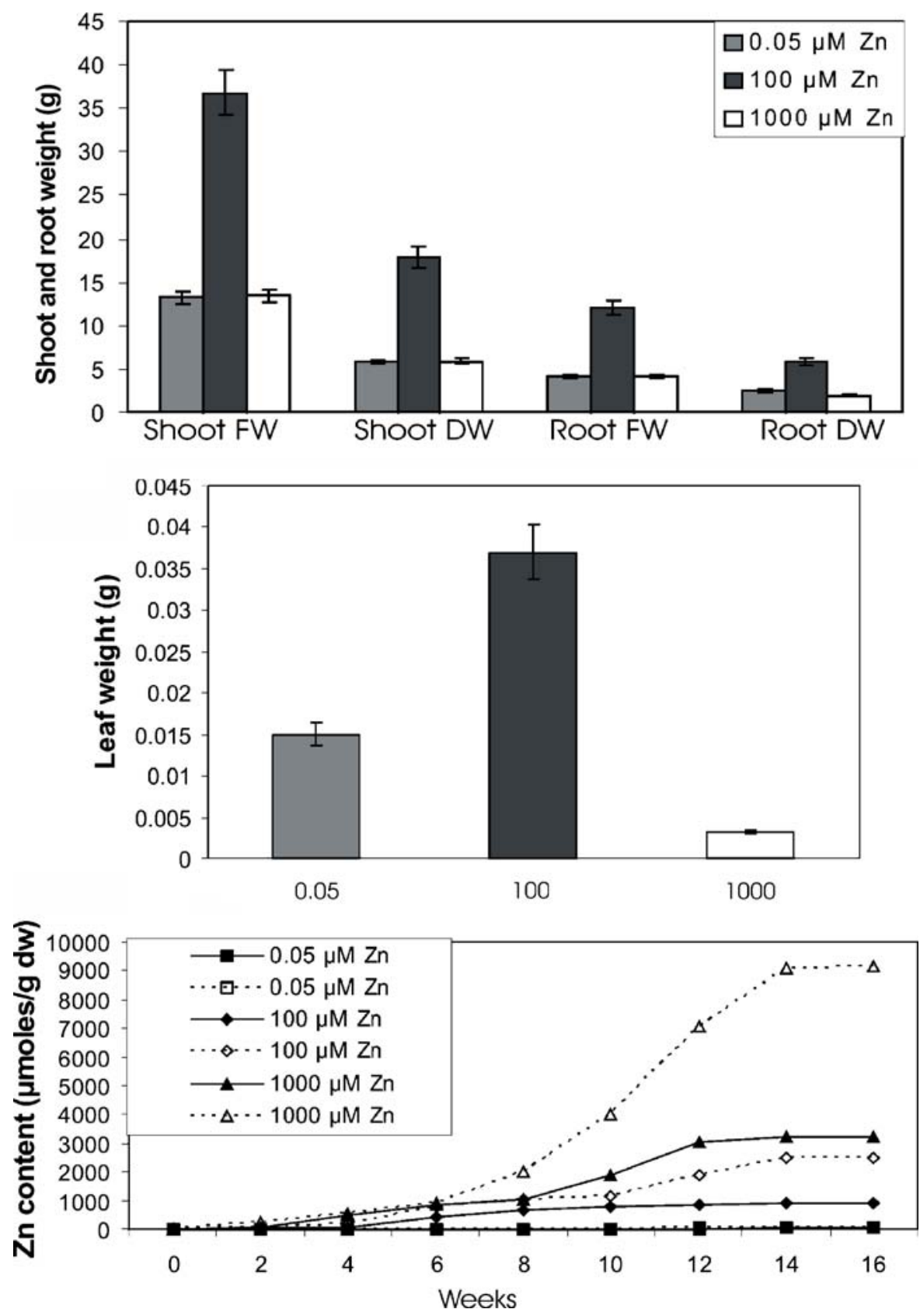

for a longer time than A. thaliana, the resulting reduction in root or shoot weight was less than for $A$. thaliana. This suggests that $T$. caerulescens is even better than $A$. thaliana in its ability to resist prolonged exposure to low $\mathrm{Zn}$ supply. This is surprising considering the assumed constitutive (over)expression of $\mathrm{Zn}$ scavenging transporters in this species compared to A. thaliana or the related non-accumulator $T$. arvense (Assunção et al. 2001; Hammond et al. 2006;
Van de Mortel et al. 2006). There is a possibility that this lack of more serious deficiency symptoms is due to the growth of $T$. caerulescens plants on medium supplied with $0.05 \mu \mathrm{M} Z n$ compared to $0 \mu \mathrm{M} Z n$ for A. thaliana. Although the $\mathrm{Zn}$ content of $A$. thaliana plants grown at $0.05 \mu \mathrm{M}$ was very low (Fig. 4), it was still detectable, which was not the case when plants were grown on $0 \mu \mathrm{M} \mathrm{Zn}$ (data not shown). However, there were no visible differences between $A$. thaliana 
plants grown on 0 or $0.05 \mu \mathrm{M}$ Zn (data not shown) and therefore we do not think this caused the absence of very serious $\mathrm{Zn}$ deficiency symptoms in $T$. caerulescens. There is also the possibility that the $T$. caerulescens plants acquired much more $\mathrm{Zn}$ than $A$. thaliana prior to hydroponic culture during germination on Zn-containing agar plates. During hydroponic culture this $\mathrm{Zn}$ may have been reallocated to prevent the development of more serious $\mathrm{Zn}$-deficiency symptoms.

While a low $\mathrm{Zn}$ concentration affects plant development, a high $\mathrm{Zn}$ concentration in plants can be toxic. Zn hyperaccumulator species seem to have found a way to deal with a high $\mathrm{Zn}$ content in the plant. The accession LC of T. caerulescens which we used has been shown before to develop the first symptoms of toxicity when exposed to concentrations of 1,000 $\mu \mathrm{M} \mathrm{Zn}$ or higher (Assunção et al. 2003b), as we also observed. Phenotypically there was not that much difference between plants growing on $\mathrm{Zn}$ deficient or high $\mathrm{Zn}$ medium. Both conditions affected plant size, leaf size and chlorosis of leaves and inflorescences. Leaf size seems to be more affected under high $\mathrm{Zn}$ than under $\mathrm{Zn}$ deficiency. Although leaf number was not determined, this may suggest that high $\mathrm{Zn}$ plants make more leaves that weigh less than $\mathrm{Zn}$ deficiency plants. When comparing $\mathrm{Zn}$ concentrations, it is clear that $T$. caerulescens preferentially accumulates in the leaves. Under all conditions the concentrations in the leaves were higher than those in the roots, whereas the opposite was the case for $A$. thaliana. Although this study shows that $\mathrm{Zn}$ deficiency and high $\mathrm{Zn}$ both affect the T. caerulescens plants in a similar way, this is likely to go through a different mechanism. Transcript analysis also indicates this (Hammond et al. 2006; Van de Mortel et al. 2006). Under both extreme conditions, the plants experience oxidative stress as indicated by the expression of oxidative stress related genes. However, only few stress-related genes are induced by both low and high $\mathrm{Zn}$ exposure and the genes are different when comparing to A. thaliana (Van de Mortel et al. 2006), suggesting that different processes have led to a similar phenotype.

Acknowledgement This research was supported by the EUMETALHOME project (HPRN-CT-2002-00243). We are grateful to Prof. Dr. Maarten Koornneef for critical reading and suggestions for the manuscript preparation.

\section{References}

Assunção AGL, da Costa Martins C, de Folter S, Vooijs R, Schat H, Aarts MGM (2001) Elevated expression of metal transporter genes in three accessions of the metal hyperaccumulator Thlaspi caerulescens. Plant Cell Environ 24:217-226

Assunção AGL, Schat H, Aarts MGM (2003a) Thlaspi caerulescens, an attractive model species to study heavy metal hyperaccumulation in plants. New Phytol 159:351-360

Assunção AGL, Bookum WM, Nelissen HJM, Vooijs R, Schat H, Ernst WHO (2003b) Differential metal-specific tolerance and accumulation patterns among Thlaspi caerulescens populations originating from different soil types. New Phytol 159:411-419

Baker A, Brooks R (1989) Terrestrial higher plants which hyperaccumulate metallic elements - a review of their distribution, ecology and phytochemistry. Biorecovery 1:81-126

Becher M, Talke IN, Krall L, Krämer U (2004) Cross-species microarray transcript profiling reveals high constitutive expression of metal homeostasis genes in shoots of the zinc hyperaccumulator Arabidopsis halleri. Plant J 37:251-268

Broadley MR, White PJ, Hammond JP, Zelko I, Lux A (2007) Zinc in plants. New Phytol 173:677-702

Brown S, Chaney R, Angle J, Baker A (1995) Zinc and cadmium uptake by hyperaccumulator Thlaspi caerulescens grown in nutrient solution. Soil Sci Soc Am J 59:125-133

Freeman J, Persans M, Nieman K, Albrecht C, Peer W, Pickering I, Salt D (2004) Increased glutathione biosynthesis plays a role in nickel tolerance in Thlaspi nickel hyperaccumulators. Plant Cell 16:2176-2191

Grusak MA, DellaPenna D (1999) Improving the nutrient composition of plants to enhance human nutrition and health. Annu. Rev Plant Physiol Plant Mol Biol 50:133-161

Guerinot ML, Eide D (1999) Zeroing in on zinc uptake in yeast and plants. Curr Opin Plant Biol 2:244-249

Hacisalihoglu G, Hart JJ, Wang YH, Cakmak I, Kochian LV (2003) Zinc efficiency is correlated with enhanced expression and activity of zinc-requiring enzymes in wheat. Plant Physiol 131:595-602

Hammond JP, Bowen HC, White PJ, Mills V, Pyke KA, Baker AJM, Whiting SN, May ST, Broadley MR (2006) A comparison of the Thlaspi caerulescens and T. arvense shoot transcriptomes. New Phytol 170:239-260

Marschner H (1995) Mineral nutrition of higher plants, 3rd edn. Academic, London, p 889

Mascarenhas J, Goralnick R (1971) Synthesis of small molecular weight RNA in the pollen tube of Tradescantia paludosa. Biochim Biophys Acta 240:56-61

McGrath SP, Sidoli CMD, Baker AJM, Reeves RD (1993) The potential for the use of metal-accumulating plants for the in situ decontamination of metal-polluted soils. In: Eijsackers HJP, Hamers T (eds) Integrated soil and sediment research: a basis for proper protection. Kluwer, Dordrecht, pp 673-677

Murashige T, Skoog F (1962) A revised medium for rapid growth and bioassays with tobacco tissue cultures. Physiol Plant 15:473-497 
Polar E (1970) The distribution of 65Zn in the cotyledons of Vicia faba and its translocation during the growth and maturation of the plant. Plant Soil 32:1-17

Reed H (1944) The growth of ovules of Pisum in relation to zinc. Am J Bot 31:193-199

Reeves R, Brooks R (1983) European species of Thlaspi L. as indicators of nickel and zinc. J Geochem Expl 18:275-283

Sharma PN, Tripathi A, Bisht SS (1995) Zinc requirement for stomatal opening in cauliflower. Plant Physiol 107:751-756

Skoog F (1940) Relationships between zinc and auxin in the growth of higher plants. Am J Bot 27:937-951

Vallee B, Auld D (1990) Zinc coordination, function, and structure of zinc enzymes and other proteins. Biochemistry 29:5647-5659

Vallee B, Falchuk K (1993) The biochemical basis of zinc physiology. Physiol Rev 73:78-118
Van de Mortel JE, Almar Villanueva L, Schat H, Kwekkeboom J, Coughlan S, Moerland PD, Ver Loren van Themaat E, Koornneef M, Aarts MGM (2006) Large expression differences in genes for iron and zinc homeostasis, stress response, and lignin biosynthesis distinguish roots of Arabidopsis thaliana and the related metal hyperaccumulator Thlaspi caerulescens. Plant Physiol 142:1127-1147

Weber M, Harada E, Vess C, Roepenack-Lahaye E, Clemens S (2004) Comparative microarray analysis of Arabidopsis thaliana and Arabidopsis halleri roots identifies nicotianamine synthase, a ZIP transporter and other genes as potential metal hyperaccumulation factors. Plant $\mathrm{J}$ 37:269-281

Worlock A, Smith R (2002) ZntB is a novel $\mathrm{Zn}^{2+}$ transporter in Salmonella enterica serovar Typhimurium. J Bacteriol 184:4369-4373 